\title{
Cellullar insights into cerebral cortical development: focusing on the locomotion mode of neuronal migration
}

\author{
Takeshi Kawauchi ${ }^{1,2,3 *}$ \\ ${ }^{1}$ Department of Physiology, Keio University School of Medicine, Tokyo, Japan, ${ }^{2}$ Precursory Research for Embryonic Science \\ and Technology (PRESTO), Japan Science and Technology Agency, Saitama, Japan, ${ }^{3}$ Laboratory of Molecular Life Science, \\ Institute of Biomedical Research and Innovation, Foundation for Biomedical Research and Innovation, Kobe, Japan
}

\section{OPEN ACCESS}

Edited by: Thomas Knöpfel,

Imperial College London, UK

Reviewed by:

Zoltan Molnar,

University of Oxford, UK

Gunnar P. H. Dietz,

Schwabe Pharma Deutschland,

Germany

*Correspondence:

Takeshi Kawauchi,

Laboratory of Molecular Life Science, Institute of Biomedical Research and Innovation, Foundation for Biomedical

Research and Innovation, 2-2

Minatojima-Minamimachi Chuo-ku,

Kobe 650-0047, Japan

takeshi-kawauchi@umin.ac.jp

Received: 08 May 2015 Accepted: 22 September 2015

Published: 07 October 2015

Citation:

Kawauchi T (2015) Cellullar insights into cerebral cortical development: focusing on the locomotion mode of neuronal migration.

Front. Cell. Neurosci. 9:394. doi: 10.3389/fncel.2015.00394
The mammalian brain consists of numerous compartments that are closely connected with each other via neural networks, comprising the basis of higher order brain functions. The highly specialized structure originates from simple pseudostratified neuroepithelium-derived neural progenitors located near the ventricle. A long journey by neurons from the ventricular side is essential for the formation of a sophisticated brain structure, including a mammalian-specific six-layered cerebral cortex. Neuronal migration consists of several contiguous steps, but the locomotion mode comprises a large part of the migration. The locomoting neurons exhibit unique features; a radial glial fiber-dependent migration requiring the endocytic recycling of $\mathrm{N}$-cadherin and a neuron-specific migration mode with dilation/swelling formation that requires the actin and microtubule organization possibly regulated by cyclin-dependent kinase 5 (Cdk5), Dcx, p27 kip1, Rac1, and POSH. Here I will introduce the roles of various cellular events, such as cytoskeletal organization, cell adhesion, and membrane trafficking, in the regulation of the neuronal migration, with particular focus on the locomotion mode.

Keywords: microtubule, actin cytoskeleton, endocytosis, JNK, Rab5, Rab11, Rab7, Rap1

\section{Introduction}

The brain is divided into many compartments, such as nuclei, layered structures, and cortical areas, allowing highly organized role allocations. The systematically allocated neuronal populations are generated from spatially restricted regions, the ventricular, and subventricular zones. Therefore, a long-distance migration from the ventricular side to the final destination is essential for constructing a functional brain. In line with this, defects in neuronal migration are associated with various neurological disorders (Gleeson and Walsh, 2000; Kawauchi and Hoshino, 2008). Several types of cortical malformations, including lissencephaly, double cortex syndrome (subcortical band heterotopia) and periventricular heterotopia (PVH), are thought to result from neuronal migration defects. These cortical malformations are frequently associated with intellectual disability and intractable epilepsy (Francis et al., 2006; Moon and Wynshaw-Boris, 2013; Reiner and Sapir, 2013; Lian and Sheen, 2015). Lis1, Dcx, Filamin A, ArfGEF2, Arx, Reelin, and several Tubulin genes (TUBA1A, TUBA8, TUBB2B, TUBB3, TUBB5, and TUBG1) are identified as causative genes 
for these cortical malformations (des Portes et al., 1998; Fox et al., 1998; Gleeson et al., 1998; Hong et al., 2000; Kitamura et al., 2002; Kato et al., 2004; Sheen et al., 2004; Keays et al., 2007; Abdollahi et al., 2009; Reiner and Sapir, 2013; Bahi-Buisson et al., 2014; Magen et al., 2015) (Figures 1A,B). Furthermore, suppression of genes related to dyslexia (e.g., DCDC2, KIAA0319), autism spectrum disorder (ASD) (e.g., Auts2, CNTNAP2) and schizophrenia (e.g., SDCCAG8) disturbs neuronal migration, although it is unclear whether the neuronal migration defect is the main cause of the pathogenesis of these neurological and psychiatric disorders (Hannula-Jouppi et al., 2005; Kamiya et al., 2005; Meng et al., 2005; Paracchini et al., 2006; Wang et al., 2006; Kähler et al., 2008; Peñagarikano et al., 2011; O'roak et al., 2012; Zhang et al., 2013a; Hori et al., 2014; Insolera et al., 2014; La Fata et al., 2014) (Figure 1B). Interestingly, in addition to these genes, several environmental factors, such as stress and inflammation, are also associated with cortical development, including neuronal migration (Stolp et al., 2012; Hashimoto-Torii et al., 2014; Ishii and Hashimoto-Torii, 2015).

In the developing cerebral cortex, neuronal migration consists of several contiguous steps (Nadarajah and Parnavelas, 2002; Cooper, 2014; Takano et al., 2015) (Figure 1A). Newly generated neurons exhibit multipolar morphology in the lower part of the intermediate zone. The multipolar neurons form an axon and a leading process almost coincidentally with retraction of other processes. The bipolar-shaped neurons are called "locomoting neurons," which migrate along radial glial fibers with unique morphological changes (the locomotion mode of neuronal migration) (Figure 2A). At the final phase of neuronal migration, they switch over from the "locomotion" into a "terminal translocation."

Most studies so far have focused on the mechanisms of the morphological changes at the early phase of neuronal migration, including the multipolar-to-bipolar transition (Kawauchi and Hoshino, 2008; Heng et al., 2010). One reason is that many cortical malformation-related gene products are involved in the multipolar-to-bipolar transition. Second, the acquirement of neuronal polarity, a key step of neuronal maturation, occurs nearly simultaneously with the multipolar-bipolar transition. Third, suppression of cytoskeletal proteins or kinases often leads to defects in the early phase of migration due to the occurrence of various morphological changes at this stage.

In contrast to the early phase of migration, our knowledge of the locomotion mode is relatively poor. However, recent morphological and cell biological analyses have uncovered unique features of locomoting neurons. In this review, I will introduce recent advances in the molecular and cellular biology of neuronal migration with particular focus on the locomotion mode.

\section{The Early Phase of Neuronal Migration}

Several steps of the early phase of neuronal migration, including the multipolar-to-bipolar transition, are required for the formation of the morphologies of the locomoting neurons. The formation of a leading process requires c-jun $\mathrm{N}$-terminal kinase (JNK) (Kawauchi et al., 2003). Filamin A (FLNA), an actin-binding protein, is also involved in the early phase of migration, possibly including the leading process formation (Nagano et al., 2004). Knockdown of Lis1, a regulator of the dynein complex, a microtubule minus end-directed motor, suppresses the multipolar-bipolar transition (Tsai et al., 2005). FLNA and Lis1 have been identified as causative genes for PVH and lissencephaly, respectively, and both knockout of FLNA and Lis1 heterodeficiency show neuronal migration defects (Hirotsune et al., 1998; Zhang et al., 2013b).

In addition, many other molecules are reported to regulate the formation of multipolar morphology (e.g., Cdk5, p27kip1, Arx, Rab5) (Kawauchi et al., 2006, 2010; Friocourt et al., 2008; Friocourt and Parnavelas, 2010) and multipolar-to-bipolar transition (e.g., Cdk5, PHF6, FMRP) (Ohshima et al., 2007; Zhang et al., 2013a; La Fata et al., 2014; Franzoni et al., 2015) at the early phase of migration (Figure 1A).

\section{The Locomotion Mode of Neuronal Migration}

The locomotion mode of neuronal migration covers the largest part of the neuronal journey, and is therefore a main contributor to proper neuronal positioning (Rakic, 2006; Nishimura et al., 2010). As described above, however, analysis of molecular mechanisms underlying the locomotion mode is difficult, because in many cases, neurons with defects in cytoskeletal proteins or kinases also show abnormalities early in neuronal migration prior to starting the locomotion (or no phenotypes). However, recent advances in in vivo cell biological approaches and novel technologies have uncovered several molecules regulating the unique features of the locomotion mode of neuronal migration. For example, a novel method, the ex vivo chemical inhibitor technique, that allows us to directly analyze molecules involved in the locomotion mode, has recently been established (Nishimura et al., 2010). Using this technique, Cdk5 and Src family kinases were shown to regulate the locomotion mode (Nishimura et al., 2010).

The locomotion mode of neuronal migration displays two major characteristics, a radial glial fiber-dependent migration and a neuron-specific unique migration mode with dilation/swelling formation and nuclear elongation (Rakic, 1972; Bellion et al., 2005; Schaar and McConnell, 2005) (Figure 2). In the next subsections, I will introduce the morphological, molecular, and cellular mechanisms of these unique characters of the locomotion mode.

\section{A Unique Migration Mode with Dilation/Swelling Formation}

Locomoting neurons exhibit distinct migration features (Bellion et al., 2005; Schaar and McConnell, 2005; Nishimura et al., 2014). (1) Locomoting neurons extend a leading process and form a cytoplasmic dilation (also referred as to "swelling" especially in tangentially migrating interneurons) at the proximal region of a leading process. (2) The nucleus in the locomoting neurons becomes elongated to enter the cytoplasmic dilation (Figure 2). 
A

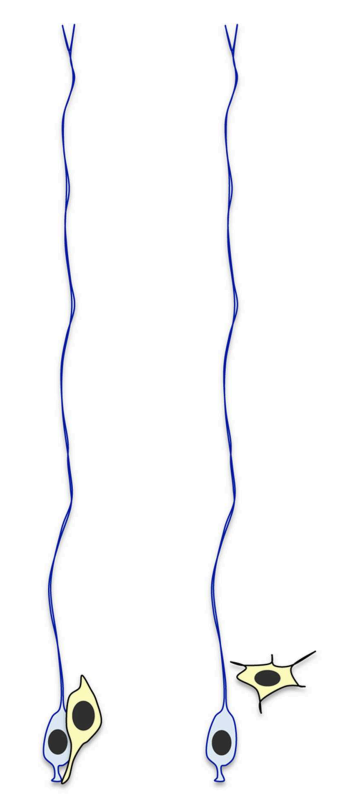

Lis1, Cdk5, p27, Arx, PHF6, JNK, Filamin A, $\mathrm{N}$-cadherin, Cx43, FMRP

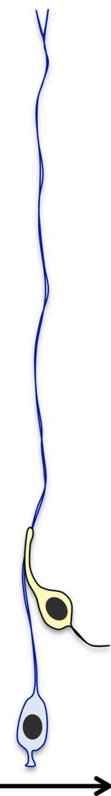

\section{Cdk5,} , Dcx, p27, JNK, Rac1, POSH, Rab5, Rab11, Cx43, $\mathrm{N}$-cadherin, Src family
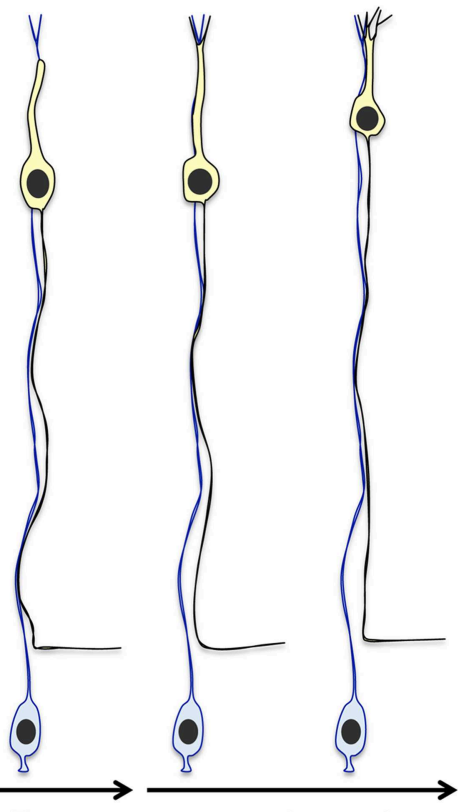

$\alpha 5 \beta 1$-Integrin, Reelin, Dab1, Rab7, PKC $\delta$

B

\begin{tabular}{|l|l|l|}
\hline Molecule & \multicolumn{1}{|c|}{ Molecular and cellular function } & \multicolumn{1}{|c|}{ Related brain disease } \\
\hline Lis1 & Regulator for dynein motor & Lissencephaly, Millar-Dicker sydrome \\
\hline Dcx & Microtubule binding and stabilizing & Lissencephaly, Subcortical band heterotopia \\
\hline Filamin A & Actin binding and crosslinking & Periventricular heterotopia \\
\hline ArfGEF2 & Membrane trafficking & Periventricular heterotopia, Microcephaly \\
\hline Reelin & Extracellular protein, Rap1 and Integrin activation & Lissencephaly, Schizophrenia, ASD \\
\hline Cdk5 & Signaling molecule, Cytoskelatal regulation & Lissencephaly \\
\hline Tubulins* & Component of microtubules & Lissencephaly, Microcephaly \\
\hline Arx & Transcription factor & Epilepsy, Lissencephaly, Intellectual disability \\
\hline Dcdc2 & DCX family, Involvement of ciliary functions (?) & Dyslexia \\
\hline DYX1C1 & Regulation of Dynein assembly and ciliary motility & Dyslexia (?) \\
\hline KIAA0319 & Single transmembrane protein & Dyslexia \\
\hline ROBO1 & Single transmembrane protein, Slit receptor & Dyslexia \\
\hline Auts2 & Transcriptional activation, Cytoskeletal regulation & ASD \\
\hline CNTNAP2 & Transmembrane protein, K+ channel clustering & ASD, Epilepsy \\
\hline Tbr1 & Transcription factor & ASD \\
\hline SDCCAG8 & Regulation of centrosomal properties and function & Schizophrenia, Intellectual disability \\
\hline Disc1 & Ndel1/Dynein regulation, Wnt/GSK3 $\beta$ signal & Schizophrenia (?) \\
\hline MDGA1 & GPI-anchored immunoglobulin superfamily & Schizophrenia \\
\hline PHF6 & Binding to PAF1 transcription elongation complex & Intellectual disability (Börjeson-Forssman-Lehmann syndrome) \\
\hline FMRP & mRNA binding, Regulation of translation & Intellectual disability (fragile X syndrome), ASD \\
\hline
\end{tabular}

* Tubulins: TUBA1A, TUBA8, TUBB2B, TUBB3, TUBB5 and TUBG1 (see Bahi-Buisson et al.)

FIGURE 1 | Molecules involved in the multi-step modes of neuronal migration and its related neurological disorders. (A) Immature neurons (light yellow cells), generated from radial glial progenitors (light blue cells) near the ventricle, migrate toward the pial surface. At the early phase of neuronal migration (the left three migrating neurons), many cytoskeletal-regulatory proteins (e.g., Lis1 and Filamin A), kinases (e.g., Cdk5 and JNK), and other proteins (e.g., p27kip1 and N-cadherin) 


\section{FIGURE 1 | Continued}

are required for proper morphological changes of migrating neurons (Kawauchi and Hoshino, 2008; Lickiss et al., 2012; Kawauchi, 2014). Interestingly, some of these molecules are also involved in neurological disorders, such as Börjeson-Forssman-Lehmann syndrome (for PHF6) (Zhang et al., 2013a; Franzoni et al., 2015), Fragile X syndrome (for FMRP) (La Fata et al., 2014) and lissencephaly (for Lis1, Cdk5, and Arx) (Friocourt and Parnavelas, 2010; Reiner and Sapir, 2013; Magen et al., 2015). Subsequently, neurons undergo the locomotion mode of neuronal migration (the middle three migrating neurons). Cdk5 and its substrates, Dcx, and p27kip1, control the dilation/swelling formation during the locomotion. POSH and Rac1 are also required for the dilation/swelling formation. $\mathrm{N}$-cadherin and its regulation by Rab5- and Rab11-dependent endocytic recycling play important roles in radial glial fiber-dependent migration of the locomoting neurons. At the final phase of migration, neurons undergo the terminal translocation mode (the right two migrating neurons). The Reelin-Dab1-C3G-Rap1-Talin-Integrin pathway regulates the terminal translocation. $\mathrm{PKC} \delta$ is also required for the terminal translocation. (B) Molecules involved in neuronal migration-related brain diseases.

The cytoplasmic dilation or swelling was first identified in 2005 as a migrating neuron-specific subcellular domain, because not only other migrating cells, such as neutrophils, keratocytes, and fibroblasts, but also static neurons do not form a cytoplasmic dilation/swelling (Bellion et al., 2005; Schaar and McConnell, 2005). Electron microscopy studies show that the cytoplasmic dilation/swelling contains the centrosome, Golgi apparatus, and microtubules. Although the centrosome frequently is a part of the cytoplasmic dilation/swelling (Bellion et al., 2005; Schaar and McConnell, 2005), suppression of dynein heavy chain or Lis1, both of which are known to regulate centrosomal positioning and nuclear forward movement in radially migrating neurons, does not disrupt cytoplasmic dilation/swelling (Tsai et al., 2007). Furthermore, mDia, an actin nucleator that acts as a downstream effector of RhoA, regulates centrosomal positioning, and nuclear translocation in tangentially migrating GABAergic interneurons. However, mDia deficiency does not impair the cytoplasmic dilation/swelling formation (Shinohara et al., 2012).

In contrast to RhoA, another Rho family small GTPase, Rac1 and its binding protein, $\mathrm{POSH}$, are required for the formation of cytoplasmic dilation/swelling in cortical excitatory neurons (Yang et al., 2012). Suppression of Rac1 by the expression of the dominant negative mutant, shRNA-mediated knockdown, or gene targeting, disturbs neuronal migration (Kawauchi et al., 2003; Chen et al., 2007; Govek et al., 2011; Yang et al., 2012). Although Racl promotes the activity of JNK, which is known to regulate leading process morphology and neuronal migration (Kawauchi et al., 2003), JNK1-suppressing neurons are able to form the cytoplasmic dilation/swelling. The area of the cytoplasmic dilation/swelling is not significantly different between control and JNK1-knockdown neurons, although the morphologies of the cytoplasmic dilation/swelling in the JNK1knockdown neurons are rough and irregular in part (Nishimura et al., 2014). Therefore, Racl and POSH are believed to control the formation of cytoplasmic dilation/swelling mainly in a JNK1independent manner.

Considering that abundant microtubules are observed in the cytoplasmic dilation/swelling, microtubule-regulatory proteins may be involved in the formation of this subcellular domain. In fact, it has been reported that Dcx (previously known as Doublecortin) and its upstream kinase, Cdk5, are required for the formation of the cytoplasmic dilation/swelling (Nishimura et al., 2014). Interestingly, both $D c x$ and $C d k 5$ are known as causative genes for lissencephaly (Gleeson et al., 1998; des Portes et al., 1998; Magen et al., 2015).
Dcx controls not only microtubule polymerization but also endocytic trafficking (Francis et al., 1999; Gleeson et al., 1999; Yap et al., 2012; Yap and Winckler, 2015), and clathrincoated pits are observed in cytoplasmic dilation/swelling (Shieh et al., 2011). Pharmacological inhibition of microtubule polymerization (nocodazole treatment) or endocytosis (dynasore treatment) by using the ex vivo chemical inhibitor technique, disturbs the formation of the cytoplasmic dilation/swelling (Nishimura et al., 2014). Consistently, knockdown of Rab5, a regulator for endocytosis and trafficking to early endosomes, shows defects similar to the dynasore treatment.

Furthermore, p $27^{\mathrm{kip} 1}$, another Cdk5 substrate, is required for the cytoplasmic dilation/swelling formation (Nishimura et al., 2014). Although p27 $7^{\mathrm{kip} 1}$ controls the G1 length in the cell cycle and promotes cell cycle exit, p2 $7^{\mathrm{kip} 1}$ also plays a role in actin reorganization through suppression of RhoA activity and activation of an actin-binding protein, Cofilin, in the multipolar processes of neurons at the early phase of migration (Kawauchi et al., 2006, 2013). In addition, p27kip1 is required for the tangential migration of cortical GABAergic interneurons via microtubule organization (Godin et al., 2012). However, it is still unclear which downstream event(s) (the regulation of actin or microtubule or something else) is important for the cytoplasmic dilation/swelling formation in the locomoting neurons.

\section{Nuclear Elongation and Forward Movement}

After the formation of the cytoplasmic dilation/swelling, the nucleus elongates, and moves into the newly formed dilation. This nuclear elongation is closely coupled with the cytoplasmic dilation/swelling formation. In fact, suppression of Cdk5, Dcx, p27 kip1, Rab5, microtubule polymerization, or endocytosis perturbs the nuclear elongation as well as dilation/swelling formation during the locomotion mode (Nishimura et al., 2014). Interestingly, however, knockdown of JNK, which does not affect the area of the cytoplasmic dilation/swelling, suppresses the nuclear elongation, suggesting that Cdk5 and JNK, both of which promote microtubule dynamics (Kawauchi et al., 2003, 2005), have different roles in the locomotion mode of migration (Nishimura et al., 2014).

The elongated nuclei are surrounded by perinuclear cagelike microtubules, which contain abundant tyrosinated tubulins, components of dynamic microtubules (Rivas and Hatten, 1995; Schaar and McConnell, 2005; Umeshima et al., 2007). The regulation of microtubule dynamics is known to require Cdk5 and JNK activities (Kawauchi et al., 2005). Cdk5 phosphorylates focal adhesion kinase (FAK) at Ser732, and 

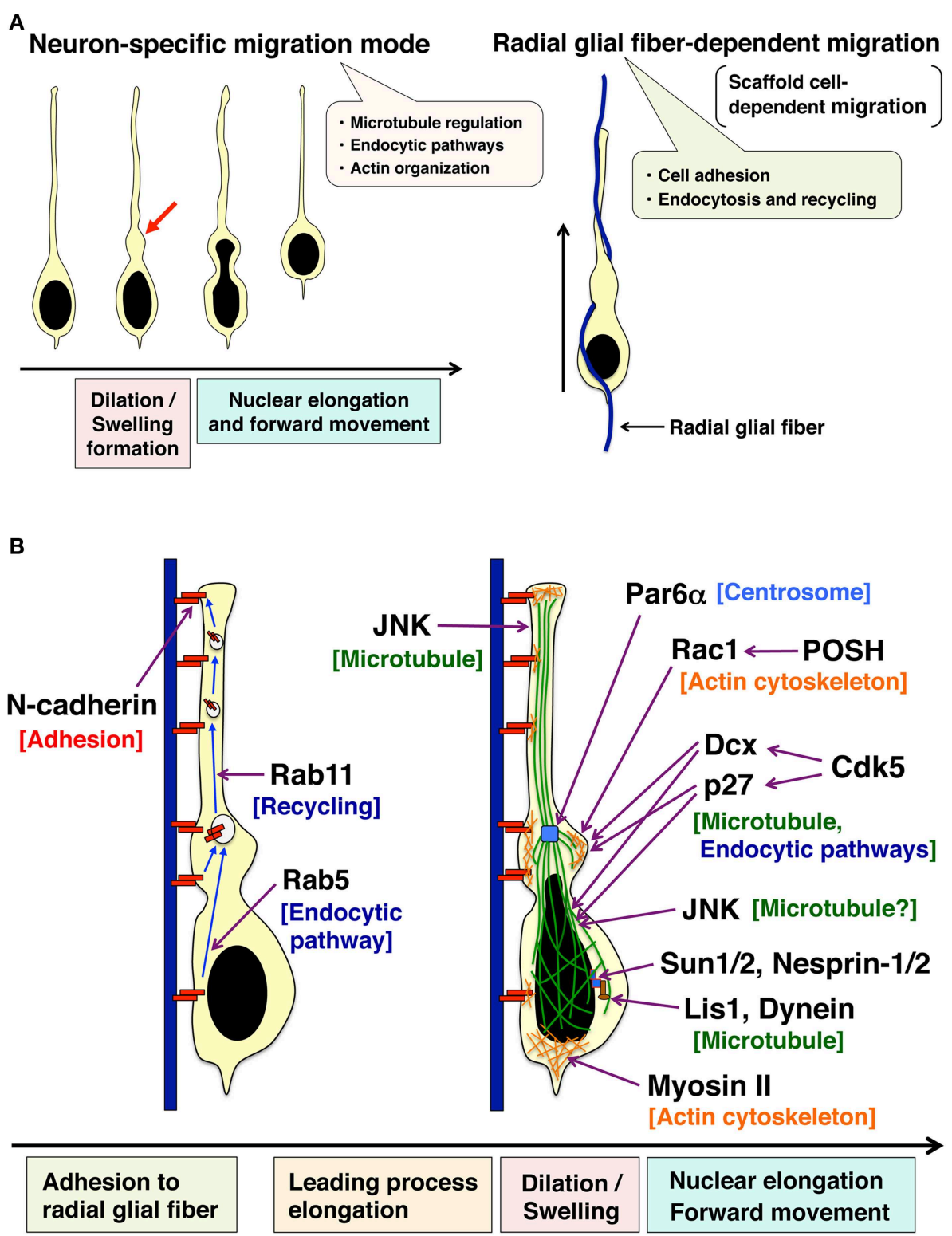

FIGURE 2 | Two unique features of the locomotion mode of neuronal migration. (A) Locomoting neurons exhibit a neuron-specific migration feature (left) and a scaffold cell-dependent migration (right). Locomoting neurons form a cytoplasmic dilation/swelling at the proximal region of a leading process, and subsequently, the nucleus shows an elongated morphology and moves into the dilation/swelling (left). Locomoting neurons also show a scaffold cell-dependent migration. They attach to and migrate along the neural progenitor-derived radial glial fibers (right). (B) Cellular events regulating two unique features of the locomotion mode of neuronal migration. $\mathrm{N}$-cadherin is involved in the adhesion to radial glial fibers. Endocytic recycling of $\mathrm{N}$-cadherin is required for the forward movement of neurons. JNK controls the leading process formation possibly through the regulation of microtubule dynamics. Par6 $\alpha$ is localized at centrosomes and regulates perinuclear cage-like microtubules. Both POSH-Rac1 and Cdk5-Dcx pathways are required for the formation of cytoplasmic dilation/swelling. Another Cdk5 substrate, p27kip1 also plays an important role in cytoplasmic dilation/swelling formation. Furthermore, Cdk5, Dcx, p27kip1 as well as JNK are involved in the nuclear elongation in the locomoting neurons. Lis, Dynein, SUN1/2, Nesprin-1/2, and Myosin II regulate the nuclear forward movement. See the main text for more details.

Ser732-phosphorylated FAK is localized on the perinuclear cagelike microtubules (Xie et al., 2003). Cdk5 deficiency or expression of the Ser732-nonphosphorylatable mutant of FAK (S732A) disturbs the nuclear elongation in migrating neurons. It is also known that overexpression of Par6 $\alpha$, which is localized at the centrosome, disrupts the perinuclear cage (Solecki et al., 2004).
The forward movement of the nuclei (nucleokinesis) requires Lis1- and dynein-mediated motor activity (see the following excellent reviews: Tsai and Gleeson, 2005; Marín et al., 2010). SUN1/2 and Nesprin-1/2, which are localized at the inner and outer membranes of the nuclear envelope, respectively, connect the nucleus to the dynein complex on microtubules 
in the locomoting neurons (Zhang et al., 2009). In addition, actomyosin-mediated contractility at the posterior end of the cell is known to play an important role in the nuclear forward movement (Schaar and McConnell, 2005; Martini and Valdeolmillos, 2010). Myosin II is also observed at the proximal region of the leading process and controls the coordinated movement of the centrosome and soma in cerebellar granule neurons (Solecki et al., 2009).

\section{A Radial Glial Fiber-dependent Migration}

Another feature of the locomotion mode of neuronal migration is migration on other cells, called a scaffold cell-dependent migration (Kawauchi, 2012) (Figure 2A). It has been suggested that Astrotactin (Astn1) is involved in the interaction between migrating neurons and Bergmann glial fibers (Adams et al., 2002). Treatment with antibodies against Astn1, but not Ncadherin and L1-CAM, inhibits the attachment of cultured cerebellar granule neurons to astroglia and glia-guided neuronal migration (Stitt and Hatten, 1990; Fishell and Hatten, 1991).

The discovery that the locomoting neurons migrate along radial glial fibers in the developing cerebral cortex was reported in 1972 (Rakic, 1972). Unlike the cerebellar granule neurons, suppression of a cell-cell adhesion molecule, N-cadherin, in the developing cerebral cortex perturbs the attachment of migrating neurons to the radial glial fibers and neuronal migration (Kawauchi et al., 2010; Shikanai et al., 2011). Importantly, a portion of $\mathrm{N}$-cadherin is internalized by Rab5-dependent endocytic pathways, and subsequently transported to the plasma membrane via Rab11-dependent recycling pathways. This active transport of $\mathrm{N}$-cadherin is essential for the radial glial fiberdependent migration of locomoting neurons in the developing cerebral cortex (Kawauchi et al., 2010).

$\mathrm{N}$-cadherin is involved in other modes of neuronal migration and adhesions between radial glial neural progenitors (Solecki, 2012). Under the control of Reelin and Rap1, N-cadherin regulates the transition from multipolar to bipolar neurons (Jossin and Cooper, 2011; Gärtner et al., 2012). N-cadherin is also required for the somal translocation mode of neuronal migration, which is applied to the early-born neurons (Franco et al., 2011). Cajal-Retzius cells in the marginal zone and somal translocating neurons express immunoglobulin-like adhesion molecules, Nectin-1 and Nectin-3, respectively, and Nectin3 upregulates $\mathrm{N}$-cadherin to promote the somal translocation mode in early corticogenesis (Gil-Sanz et al., 2013). Interestingly, $\mathrm{N}$-cadherin has also been implicated for a role in the tangential migration of cortical interneurons (Luccardini et al., 2013, 2015).

In addition to $\mathrm{N}$-cadherin, other cell adhesion molecules, such as Connexin 43 (Cx43), Cx26, and JAM-C, have been shown to control neuronal migration. $\mathrm{Cx} 43$ and $\mathrm{Cx} 26$, gap junction proteins, stabilize a leading process on the radial glial fibers via enhancement of cell-cell adhesion, rather than formation of an aqueous channel (Elias et al., 2007). FAK promotes the assembly of $\mathrm{Cx} 26$ at contact sites between the locomoting neurons and radial glial fibers (Valiente et al., 2011). Interestingly, Cx43 is also involved in the formation of multipolar morphologies at the early phase of neuronal migration (Liu et al., 2012). Cx43 upregulates $\mathrm{p} 27^{\mathrm{kip} 1}$, which controls the multipolar morphologies through actin reorganization (Kawauchi et al., 2006). JAM-C and its binding adaptor protein, Pard3, are localized at the tight junctions in epithelial cells. However, in migrating cerebellar granule neurons, Pard3A promotes the recruitment of JAM-C to neuron-neuron or neuron-glial cell contacts (Famulski et al., 2010).

Integrin heterodimers are mainly involved in cell-to-extra cellular matrix adhesion (Kawauchi, 2012). It has been reported that treatment with antibodies against $\beta 1$-integrin suppresses radial glial fiber-dependent neuronal migration in vitro (Anton et al., 1999). However, NEX promoter-mediated conditional knockout of $\beta 1$-integrin in neurons revealed no migration defects in the cortical six-layered structures, while Nestin promotermediated disruption of $\beta 1$-integrin in both neurons and radial glial progenitors resulted in disorganization of radial glial fibers and cortical laminae, similar to type II-lissencephaly (GrausPorta et al., 2001; Belvindrah et al., 2007).

\section{The Final Phase of Neuronal Migration After the Locomotion: A Terminal Translocation Mode}

At the final phase of neuronal migration when the leading process reaches the marginal zone, neurons undergo a shortdistance migration in a radial glial fiber-independent manner (Figure 1A). N-cadherin expression is decreased at the cell soma of neurons undergoing terminal translocation (Kawauchi et al., 2010). Suppression of Rab7, a regulator for lysosomal degradation pathways, leads to a defect in the terminal translocation. Taken together with the involvement of Rab7 in the degradation of $\mathrm{N}$-cadherin in vitro, it suggests that Rab7dependent lysosomal degradation of $\mathrm{N}$-cadherin at the cell soma is required for the terminal translocation (Kawauchi et al., 2010). N-cadherin is still expressed in the distal region of the leading processes (immature dendrites) in terminal translocating neurons (Kawauchi et al., 2010), and therefore might play a role in the terminal translocation as it has been reported to control somal translocation during early corticogenesis (Franco et al., 2011).

Additionally, involvement of other cell adhesion molecules, such as $\alpha 5 \beta 1$-integrin, a receptor for fibronectin, and L1$\mathrm{CAM}$, and Protein kinase $\mathrm{C}$ delta $(\mathrm{PKC} \delta$ ) has been reported (Nishimura et al., 2010; Sekine et al., 2012; Tonosaki et al., 2014) (Figure 1A). Suppression of either $\alpha 5$-integrin or $\beta 1$ integrin perturbs terminal translocation (Sekine et al., 2012). Reelin-mediated activation of Rap1 promotes the recruitment of Talin to the plasma membrane, which activates the Integrin heterodimers possibly through direct binding to the cytoplasmic region of $\beta 1$-integrin (Sekine et al., 2012). As described above, Reelin also enhances the activation of Rap1 during the early phase of neuronal migration (Jossin and Cooper, 2011). Recent studies have revealed that two guanine-nucleotide exchange factors (GEFs), C3G, and RapGEF2, differentially activate Rap1 at the final or early phases of migration, respectively (Ye et al., 2014). However, defects in the multipolar-to-bipolar transition have been reported in C3G-knockout brains (Voss et al., 2008), 
suggesting that $\mathrm{C} 3 \mathrm{G}$ may also be required for the early phase of neuronal migration.

\section{Conclusion}

From the 1990's, several key molecules involved in neuronal migration, such as Lis1, Dcx, FLNA, and Reelin, have been identified mainly by the use of molecular genetics. Furthermore, recent in vivo and ex vivo cell biological techniques, including in vivo electroporation, slice culture methods, time-lapse imaging and electron microscopy analyses, have uncovered essential roles for dynamic regulation of cytoskeleton and cell adhesion in neuronal migration. In the locomoting neurons, the formation of dilation/swelling requires proper regulation of microtubules, actin cytoskeleton, and endocytic pathways (Figure 2). Another feature of locomotion, a radial glial fiber-dependent migration, depends on the membrane trafficking-mediated remodeling of

\section{References}

Abdollahi, M. R., Morrison, E., Sirey, T., Molnar, Z., Hayward, B. E., Carr, I. M., et al. (2009). Mutation of the variant alpha-tubulin TUBA8 results in polymicrogyria with optic nerve hypoplasia. Am. J. Hum. Genet. 85, 737-744. doi: 10.1016/j.ajhg.2009.10.007

Adams, N. C., Tomoda, T., Cooper, M., Dietz, G., and Hatten, M. E. (2002). Mice that lack astrotactin have slowed neuronal migration. Development 129, 965-972. Available online at: http://dev.biologists.org/content/129/4/965.long

Anton, E. S., Kreidberg, J. A., and Rakic, P. (1999). Distinct functions of alpha3 and alpha(v) integrin receptors in neuronal migration and laminar organization of the cerebral cortex. Neuron 22, 277-289. doi: 10.1016/S0896-6273(00) 81089-2

Bahi-Buisson, N., Poirier, K., Fourniol, F., Saillour, Y., Valence, S., Lebrun, N., et al. (2014). The wide spectrum of tubulinopathies: what are the key features for the diagnosis? Brain 137, 1676-1700. doi: 10.1093/brain/awu082

Bellion, A., Baudoin, J. P., Alvarez, C., Bornens, M., and Metin, C. (2005). Nucleokinesis in tangentially migrating neurons comprises two alternating phases: forward migration of the Golgi/centrosome associated with centrosome splitting and myosin contraction at the rear. J. Neurosci. 25, 5691-5699. doi: 10.1523/JNEUROSCI.1030-05.2005

Belvindrah, R., Graus-Porta, D., Goebbels, S., Nave, K. A., and Muller, U. (2007). Betal integrins in radial glia but not in migrating neurons are essential for the formation of cell layers in the cerebral cortex. J. Neurosci. 27, 13854-13865. doi: 10.1523/JNEUROSCI.4494-07.2007

Chen, L., Liao, G., Waclaw, R. R., Burns, K. A., Linquist, D., Campbell, K., et al. (2007). Racl controls the formation of midline commissures and the competency of tangential migration in ventral telencephalic neurons. J. Neurosci. 27, 3884-3893. doi: 10.1523/JNEUROSCI.3509-06.2007

Cooper, J. A. (2014). Molecules and mechanisms that regulate multipolar migration in the intermediate zone. Front. Cell. Neurosci. 8:386. doi: 10.3389/fncel.2014.00386

des Portes, V., Pinard, J. M., Billuart, P., Vinet, M. C., Koulakoff, A., Carrié, A., et al. (1998). A novel CNS gene required for neuronal migration and involved in X-linked subcortical laminar heterotopia and lissencephaly syndrome. Cell 92, 51-61. doi: 10.1016/S0092-8674(00)80898-3

Elias, L. A., Wang, D. D., and Kriegstein, A. R. (2007). Gap junction adhesion is necessary for radial migration in the neocortex. Nature 448, 901-907. doi: 10.1038 /nature06063

Famulski, J. K., Trivedi, N., Howell, D., Yang, Y., Tong, Y., Gilbertson, R., et al. (2010). Siah regulation of Pard3A controls neuronal cell adhesion during germinal zone exit. Science 330, 1834-1838. doi: 10.1126/science.1198480

Fishell, G., and Hatten, M. E. (1991). Astrotactin provides a receptor system for CNS neuronal migration. Development 113, 755-765. the cell adhesion complex (Figure 2). Thus, molecular pieces, identified from molecular genetics and in vivo electroporation, begin to take shape. However, the spatio-temporal regulation of these cellular events remains unclear. Furthermore, the dynamic behavior of each endosome in migrating neurons in cortical slices remains to be observed. Continual technological advances in in vivo cell biology and related research fields will shed light on unsolved questions to help us better understand the whole picture of cerebral cortical development.

\section{Acknowledgments}

The author thanks Dr. Ruth T. Yu for critical reading of the manuscript. Research in the author's group is supported by research grants from the JST PRESTO and the JSPS KAKENHI (26290015 and 26110718).

Fox, J. W., Lamperti, E. D., Eksioglu, Y. Z., Hong, S. E., Feng, Y., Graham, D. A., et al. (1998). Mutations in filamin 1 prevent migration of cerebral cortical neurons in human periventricular heterotopia. Neuron 21, 1315-1325. doi: 10.1016/S0896-6273(00)80651-0

Francis, F., Koulakoff, A., Boucher, D., Chafey, P., Schaar, B., Vinet, M. C., et al. (1999). Doublecortin is a developmentally regulated, microtubuleassociated protein expressed in migrating and differentiating neurons. Neuron 23, 247-256. doi: 10.1016/S0896-6273(00)80777-1

Francis, F., Meyer, G., Fallet-Bianco, C., Moreno, S., Kappeler, C., Socorro, A. C., et al. (2006). Human disorders of cortical development: from past to present. Eur. J. Neurosci. 23, 877-893. doi: 10.1111/j.1460-9568.2006.04649.x

Franco, S. J., Martinez-Garay, I., Gil-Sanz, C., Harkins-Perry, S. R., and Muller, U. (2011). Reelin regulates cadherin function via Dab1/Rap1 to control neuronal migration and lamination in the neocortex. Neuron 69, 482-497. doi: 10.1016/j.neuron.2011.01.003

Franzoni, E., Booker, S. A., Parthasarathy, S., Rehfeld, F., Grosser, S., Srivatsa, S., et al. (2015). miR-128 regulates neuronal migration, outgrowth and intrinsic excitability via the intellectual disability gene Phf6. Elife 4:e04263. doi: 10.7554/eLife.04263

Friocourt, G., Kanatani, S., Tabata, H., Yozu, M., Takahashi, T., Antypa, M., et al. (2008). Cell-autonomous roles of ARX in cell proliferation and neuronal migration during corticogenesis. J. Neurosci. 28, 5794-5805. doi: 10.1523/JNEUROSCI.1067-08.2008

Friocourt, G., and Parnavelas, J. G. (2010). Mutations in ARX Result in Several Defects Involving GABAergic Neurons. Front. Cell. Neurosci. 4:4. doi: 10.3389/fncel.2010.00004

Gärtner, A., Fornasiero, E. F., Munck, S., Vennekens, K., Seuntjens, E., Huttner, W. B., et al. (2012). N-cadherin specifies first asymmetry in developing neurons. EMBO J. 31, 1893-1903. doi: 10.1038/emboj.2012.41

Gil-Sanz, C., Franco, S. J., Martinez-Garay, I., Espinosa, A., Harkins-Perry, S., and Muller, U. (2013). Cajal-Retzius cells instruct neuronal migration by coincidence signaling between secreted and contact-dependent guidance cues. Neuron 79, 461-477. doi: 10.1016/j.neuron.2013.06.040

Gleeson, J. G., Allen, K. M., Fox, J. W., Lamperti, E. D., Berkovic, S., Scheffer, I., et al. (1998). Doublecortin, a brain-specific gene mutated in human X-linked lissencephaly and double cortex syndrome, encodes a putative signaling protein. Cell 92, 63-72. doi: 10.1016/S0092-8674(00) 80899-5

Gleeson, J. G., Lin, P. T., Flanagan, L. A., and Walsh, C. A. (1999). Doublecortin is a microtubule-associated protein and is expressed widely by migrating neurons. Neuron 23, 257-271. doi: 10.1016/S0896-6273(00)80778-3

Gleeson, J. G., and Walsh, C. A. (2000). Neuronal migration disorders: from genetic diseases to developmental mechanisms. Trends Neurosci. 23, 352-359. doi: 10.1016/S0166-2236(00)01607-6 
Godin, J. D., Thomas, N., Laguesse, S., Malinouskaya, L., Close, P., Malaise, O., et al. (2012). p27(Kipl) Is a microtubule-associated protein that promotes microtubule polymerization during neuron migration. Dev. Cell 23, 729-744. doi: 10.1016/j.devcel.2012.08.006

Govek, E. E., Hatten, M. E., and van Aelst, L. (2011). The role of Rho GTPase proteins in CNS neuronal migration. Dev. Neurobiol. 71, 528-553. doi: 10.1002/dneu.20850

Graus-Porta, D., Blaess, S., Senften, M., Littlewood-Evans, A., Damsky, C., Huang, Z., et al. (2001). Beta1-class integrins regulate the development of laminae and folia in the cerebral and cerebellar cortex. Neuron 31, 367-379. doi: 10.1016/S0896-6273(01)00374-9

Hannula-Jouppi, K., Kaminen-Ahola, N., Taipale, M., Eklund, R., Nopola-Hemmi, J., Kaariainen, H., et al. (2005). The axon guidance receptor gene ROBO1 is a candidate gene for developmental dyslexia. PLoS Genet. 1:e50. doi: 10.1371/journal.pgen.0010050

Hashimoto-Torii, K., Torii, M., Fujimoto, M., Nakai, A., El Fatimy, R., Mezger, V., et al. (2014). Roles of heat shock factor 1 in neuronal response to fetal environmental risks and its relevance to brain disorders. Neuron 82, 560-572. doi: 10.1016/j.neuron.2014.03.002

Heng, J. I., Chariot, A., and Nguyen, L. (2010). Molecular layers underlying cytoskeletal remodelling during cortical development. Trends Neurosci. 33, 38-47. doi: 10.1016/j.tins.2009.09.003

Hirotsune, S., Fleck, M. W., Gambello, M. J., Bix, G. J., Chen, A., Clark, G. D., et al. (1998). Graded reduction of Pafahlb1 (Lis1) activity results in neuronal migration defects and early embryonic lethality. Nat. Genet. 19, 333-339. doi: $10.1038 / 1221$

Hong, S. E., Shugart, Y. Y., Huang, D. T., Shahwan, S. A., Grant, P. E., Hourihane, J. O., et al. (2000). Autosomal recessive lissencephaly with cerebellar hypoplasia is associated with human RELN mutations. Nat. Genet. 26, 93-96. doi: $10.1038 / 79246$

Hori, K., Nagai, T., Shan, W., Sakamoto, A., Taya, S., Hashimoto, R., et al. (2014). Cytoskeletal regulation by AUTS2 in neuronal migration and neuritogenesis. Cell Rep. 9, 2166-2179. doi: 10.1016/j.celrep.2014.11.045

Insolera, R., Shao, W., Airik, R., Hildebrandt, F., and Shi, S. H. (2014). SDCCAG8 regulates pericentriolar material recruitment and neuronal migration in the developing cortex. Neuron 83, 805-822. doi: 10.1016/j.neuron.2014.06.029

Ishii, S., and Hashimoto-Torii, K. (2015). Impact of prenatal environmental stress on cortical development. Front. Cell. Neurosci. 9:207. doi: 10.3389/fncel.2015.00207

Jossin, Y., and Cooper, J. A. (2011). Reelin, Rap1 and N-cadherin orient the migration of multipolar neurons in the developing neocortex. Nat. Neurosci. 14, 697-703. doi: 10.1038/nn.2816

Kähler, A. K., Djurovic, S., Kulle, B., Jönsson, E. G., Agartz, I., Hall, H., et al. (2008). Association analysis of schizophrenia on 18 genes involved in neuronal migration: MDGA1 as a new susceptibility gene. Am. J. Med. Genet. B Neuropsychiatr. Genet. 147B, 1089-1100. doi: 10.1002/ajmg.b.30726

Kamiya, A., Kubo, K., Tomoda, T., Takaki, M., Youn, R., Ozeki, Y., et al. (2005). A schizophrenia-associated mutation of DISC1 perturbs cerebral cortex development. Nat. Cell Biol. 7, 1167-1178. doi: 10.1038/ncb1328

Kato, M., Das, S., Petras, K., Kitamura, K., Morohashi, K., Abuelo, D. N., et al. (2004). Mutations of ARX are associated with striking pleiotropy and consistent genotype-phenotype correlation. Hum. Mutat. 23, 147-159. doi: 10.1002/humu. 10310

Kawauchi, T. (2012). Cell adhesion and its endocytic regulation in cell migration during neural development and cancer metastasis. Int. J. Mol. Sci. 13, 4564-4590. doi: 10.3390/ijms13044564

Kawauchi, T. (2014). Cdk5 regulates multiple cellular events in neural development, function and disease. Dev. Growth Differ. 56, 335-348. doi: 10.1111/dgd.12138

Kawauchi, T., Chihama, K., Nabeshima, Y., and Hoshino, M. (2003). The in vivo roles of STEF/Tiam1, Rac1 and JNK in cortical neuronal migration. EMBO J. 22, 4190-4201. doi: 10.1093/emboj/cdg413

Kawauchi, T., Chihama, K., Nabeshima, Y., and Hoshino, M. (2006). Cdk5 phosphorylates and stabilizes p27kip1 contributing to actin organization and cortical neuronal migration. Nat. Cell Biol. 8, 17-26. doi: 10.1038/ncb1338

Kawauchi, T., Chihama, K., Nishimura, Y. V., Nabeshima, Y., and Hoshino, M. (2005). MAP1B phosphorylation is differentially regulated by Cdk5/p35, Cdk5/p25, and JNK. Biochem. Biophys. Res. Commun. 331, 50-55. doi: 10.1016/j.bbrc.2005.03.132
Kawauchi, T., and Hoshino, M. (2008). Molecular pathways regulating cytoskeletal organization and morphological changes in migrating neurons. Dev. Neurosci. 30, 36-46. doi: 10.1159/000109850

Kawauchi, T., Sekine, K., Shikanai, M., Chihama, K., Tomita, K., Kubo, K., et al. (2010). Rab GTPases-dependent endocytic pathways regulate neuronal migration and maturation through $\mathrm{N}$-cadherin trafficking. Neuron 67, 588-602. doi: 10.1016/j.neuron.2010.07.007

Kawauchi, T., Shikanai, M., and Kosodo, Y. (2013). Extra-cell cycle regulatory functions of cyclin-dependent kinases (CDK) and CDK inhibitor proteins contribute to brain development and neurological disorders. Genes Cells 18, 176-194. doi: 10.1111/gtc.12029

Keays, D. A., Tian, G., Poirier, K., Huang, G. J., Siebold, C., Cleak, J., et al. (2007). Mutations in alpha-tubulin cause abnormal neuronal migration in mice and lissencephaly in humans. Cell 128, 45-57. doi: 10.1016/j.cell.2006.12.017

Kitamura, K., Yanazawa, M., Sugiyama, N., Miura, H., Iizuka-Kogo, A., Kusaka, M., et al. (2002). Mutation of ARX causes abnormal development of forebrain and testes in mice and X-linked lissencephaly with abnormal genitalia in humans. Nat. Genet. 32, 359-369. doi: 10.1038/ng1009

La Fata, G., Gartner, A., Dominguez-Iturza, N., Dresselaers, T., Dawitz, J., Poorthuis, R. B., et al. (2014). FMRP regulates multipolar to bipolar transition affecting neuronal migration and cortical circuitry. Nat. Neurosci. 17, 1693-1700. doi: 10.1038/nn.3870

Lian, G., and Sheen, V. L. (2015). Cytoskeletal proteins in cortical development and disease: actin associated proteins in periventricular heterotopia. Front. Cell. Neurosci. 9:99. doi: 10.3389/fncel.2015.00099

Lickiss, T., Cheung, A. F., Hutchinson, C. E., Taylor, J. S., and Molnár, Z. (2012). Examining the relationship between early axon growth and transcription factor expression in the developing cerebral cortex. J. Anat. 220, 201-211. doi: 10.1111/j.1469-7580.2011.01466.x

Liu, X., Sun, L., Torii, M., and Rakic, P. (2012). Connexin 43 controls the multipolar phase of neuronal migration to the cerebral cortex. Proc. Natl. Acad. Sci. U.S.A. 109, 8280-8285. doi: 10.1073/pnas.1205880109

Luccardini, C., Hennekinne, L., Viou, L., Yanagida, M., Murakami, F., Kessaris, N., et al. (2013). N-cadherin sustains motility and polarity of future cortical interneurons during tangential migration. J. Neurosci. 33, 18149-18160. doi: 10.1523/JNEUROSCI.0593-13.2013

Luccardini, C., Leclech, C., Viou, L., Rio, J. P., and Métin, C. (2015). Cortical interneurons migrating on a pure substrate of $\mathrm{N}$-cadherin exhibit fast synchronous centrosomal and nuclear movements and reduced ciliogenesis. Front. Cell. Neurosci. 9:286. doi: 10.3389/fncel.2015.00286

Magen, D., Ofir, A., Berger, L., Goldsher, D., Eran, A., Katib, N., et al. (2015). Autosomal recessive lissencephaly with cerebellar hypoplasia is associated with a loss-of-function mutation in CDK5. Hum. Genet. 134, 305-314. doi: 10.1007/s00439-014-1522-5

Marín, O., Valiente, M., Ge, X., and Tsai, L. H. (2010). Guiding neuronal cell migrations. Cold Spring Harb. Perspect. Biol. 2:a001834. doi: 10.1101/cshperspect.a001834

Martini, F. J., and Valdeolmillos, M. (2010). Actomyosin contraction at the cell rear drives nuclear translocation in migrating cortical interneurons. J. Neurosci. 30, 8660-8670. doi: 10.1523/JNEUROSCI.1962-10.2010

Meng, H., Smith, S. D., Hager, K., Held, M., Liu, J., Olson, R. K., et al. (2005). DCDC2 is associated with reading disability and modulates neuronal development in the brain. Proc. Natl. Acad. Sci. U.S.A. 102, 17053-17058. doi: 10.1073/pnas.0508591102

Moon, H. M., and Wynshaw-Boris, A. (2013). Cytoskeleton in action: lissencephaly, a neuronal migration disorder. Wiley Interdiscip. Rev. Dev. Biol. 2, 229-245. doi: 10.1002/wdev.67

Nadarajah, B., and Parnavelas, J. G. (2002). Modes of neuronal migration in the developing cerebral cortex. Nat. Rev. Neurosci. 3, 423-432. doi: 10.1038/nrn845

Nagano, T., Morikubo, S., and Sato, M. (2004). Filamin A and FILIP (Filamin A-Interacting Protein) regulate cell polarity and motility in neocortical subventricular and intermediate zones during radial migration. J. Neurosci. 24 , 9648-9657. doi: 10.1523/JNEUROSCI.2363-04.2004

Nishimura, Y. V., Sekine, K., Chihama, K., Nakajima, K., Hoshino, M., Nabeshima, Y., et al. (2010). Dissecting the factors involved in the locomotion mode of neuronal migration in the developing cerebral cortex. J. Biol. Chem. 285, 5878-5887. doi: 10.1074/jbc.M109.033761

Nishimura, Y. V., Shikanai, M., Hoshino, M., Ohshima, T., Nabeshima, Y., Mizutani, K., et al. (2014). Cdk5 and its substrates, Dcx and p27kip1, regulate 
cytoplasmic dilation formation and nuclear elongation in migrating neurons. Development 141, 3540-3550. doi: 10.1242/dev.111294

Ohshima, T., Hirasawa, M., Tabata, H., Mutoh, T., Adachi, T., Suzuki, H., et al. (2007). Cdk5 is required for multipolar-to-bipolar transition during radial neuronal migration and proper dendrite development of pyramidal neurons in the cerebral cortex. Development 134, 2273-2282. doi: 10.1242/dev.02854

O'roak, B. J., Vives, L., Fu, W., Egertson, J. D., Stanaway, I. B., Phelps, I. G., et al. (2012). Multiplex targeted sequencing identifies recurrently mutated genes in autism spectrum disorders. Science 338, 1619-1622. doi: $10.1126 /$ science. 1227764

Paracchini, S., Thomas, A., Castro, S., Lai, C., Paramasivam, M., Wang, Y., et al. (2006). The chromosome $6 p 22$ haplotype associated with dyslexia reduces the expression of KIAA0319, a novel gene involved in neuronal migration. Hum. Mol. Genet. 15, 1659-1666. doi: 10.1093/hmg/ddl089

Peñagarikano, O., Abrahams, B. S., Herman, E. I., Winden, K. D., Gdalyahu, A., Dong, H., et al. (2011). Absence of CNTNAP2 leads to epilepsy, neuronal migration abnormalities, and core autism-related deficits. Cell 147, 235-246. doi: 10.1016/j.cell.2011.08.040

Rakic, P. (1972). Mode of cell migration to the superficial layers of fetal monkey neocortex. J. Comp. Neurol. 145, 61-83. doi: 10.1002/cne.901450105

Rakic, P. (2006). A century of progress in corticoneurogenesis: from silver impregnation to genetic engineering. Cereb. Cortex 16(Suppl. 1), i3-i17. doi: 10.1093/cercor/bhk036

Reiner, O., and Sapir, T. (2013). LIS1 functions in normal development and disease. Curr. Opin. Neurobiol. 23, 951-956. doi: 10.1016/j.conb.2013.08.001

Rivas, R. J., and Hatten, M. E. (1995). Motility and cytoskeletal organization of migrating cerebellar granule neurons. J. Neurosci. 15, 981-989.

Schaar, B. T., and McConnell, S. K. (2005). Cytoskeletal coordination during neuronal migration. Proc. Natl. Acad. Sci. U.S.A. 102, 13652-13657. doi: 10.1073/pnas.0506008102

Sekine, K., Kawauchi, T., Kubo, K., Honda, T., Herz, J., Hattori, M., et al. (2012). Reelin controls neuronal positioning by promoting cell-matrix adhesion via inside-out activation of integrin alpha5beta1. Neuron 76, 353-369. doi: 10.1016/j.neuron.2012.07.020

Sheen, V. L., Ganesh, V. S., Topcu, M., Sebire, G., Bodell, A., Hill, R. S., et al. (2004). Mutations in ARFGEF2 implicate vesicle trafficking in neural progenitor proliferation and migration in the human cerebral cortex. Nat. Genet. 36, 69-76. doi: $10.1038 /$ ng 1276

Shieh, J. C., Schaar, B. T., Srinivasan, K., Brodsky, F. M., and McConnell, S. K. (2011). Endocytosis regulates cell soma translocation and the distribution of adhesion proteins in migrating neurons. PLOS ONE 6:e17802. doi: 10.1371/journal.pone.0017802

Shikanai, M., Nakajima, K., and Kawauchi, T. (2011). N-cadherin regulates radial glial fiber-dependent migration of cortical locomoting neurons. Commun. Integr. Biol. 4, 326-330. doi: 10.4161/cib.4.3.14886

Shinohara, R., Thumkeo, D., Kamijo, H., Kaneko, N., Sawamoto, K., Watanabe, K., et al. (2012). A role for mDia, a Rho-regulated actin nucleator, in tangential migration of interneuron precursors. Nat. Neurosci. 15, 373-380. doi: $10.1038 / \mathrm{nn} .3020$

Solecki, D. J. (2012). Sticky situations: recent advances in control of cell adhesion during neuronal migration. Curr. Opin. Neurobiol. 22, 791-798. doi: 10.1016/j.conb.2012.04.010

Solecki, D. J., Model, L., Gaetz, J., Kapoor, T. M., and Hatten, M. E. (2004). Par6alpha signaling controls glial-guided neuronal migration. Nat. Neurosci. 7, 1195-1203. doi: $10.1038 / \mathrm{nn} 1332$

Solecki, D. J., Trivedi, N., Govek, E. E., Kerekes, R. A., Gleason, S. S., and Hatten, M. E. (2009). Myosin II motors and F-actin dynamics drive the coordinated movement of the centrosome and soma during CNS glial-guided neuronal migration. Neuron 63, 63-80. doi: 10.1016/j.neuron.2009.05.028

Stitt, T. N., and Hatten, M. E. (1990). Antibodies that recognize astrotactin block granule neuron binding to astroglia. Neuron 5, 639-649. doi: 10.1016/08966273(90)90218-5

Stolp, H., Neuhaus, A., Sundramoorthi, R., and Molnár, Z. (2012). The long and the short of it: gene and environment interactions during early cortical development and consequences for long-term neurological disease. Front. Psychiatry 3:50. doi: 10.3389/fpsyt.2012.00050

Takano, T., Xu, C., Funahashi, Y., Namba, T., and Kaibuchi, K. (2015). Neuronal polarization. Development 142, 2088-2093. doi: 10.1242/dev.114454
Tonosaki, M., Itoh, K., Umekage, M., Kishimoto, T., Yaoi, T., Lemmon, V. P., et al. (2014). Llcam is crucial for cell locomotion and terminal translocation of the Soma in radial migration during murine corticogenesis. PLoS ONE 9:e86186. doi: 10.1371/journal.pone.0086186

Tsai, J. W., Bremner, K. H., and Vallee, R. B. (2007). Dual subcellular roles for LIS1 and dynein in radial neuronal migration in live brain tissue. Nat. Neurosci. 10, 970-979. doi: 10.1038/nn1934

Tsai, J. W., Chen, Y., Kriegstein, A. R., and Vallee, R. B. (2005). LIS1 RNA interference blocks neural stem cell division, morphogenesis, and motility at multiple stages. J. Cell Biol. 170, 935-945. doi: 10.1083/jcb.200505166

Tsai, L. H., and Gleeson, J. G. (2005). Nucleokinesis in neuronal migration. Neuron 46, 383-388. doi: 10.1016/j.neuron.2005.04.013

Umeshima, H., Hirano, T., and Kengaku, M. (2007). Microtubule-based nuclear movement occurs independently of centrosome positioning in migrating neurons. Proc. Natl. Acad. Sci. U.S.A. 104, 16182-16187. doi: 10.1073/pnas.0708047104

Valiente, M., Ciceri, G., Rico, B., and Marín, O. (2011). Focal adhesion kinase modulates radial glia-dependent neuronal migration through connexin-26. J. Neurosci. 31, 11678-11691. doi: 10.1523/JNEUROSCI.2678-11.2011

Voss, A. K., Britto, J. M., Dixon, M. P., Sheikh, B. N., Collin, C., Tan, S. S., et al. (2008). C3G regulates cortical neuron migration, preplate splitting and radial glial cell attachment. Development 135, 2139-2149. doi: 10.1242/dev. 016725

Wang, Y., Paramasivam, M., Thomas, A., Bai, J., Kaminen-Ahola, N., Kere, J., et al. (2006). DYX1C1 functions in neuronal migration in developing neocortex. Neuroscience 143, 515-522. doi: 10.1016/j.neuroscience.2006. 08.022

Xie, Z., Sanada, K., Samuels, B. A., Shih, H., and Tsai, L. H. (2003). Serine 732 phosphorylation of FAK by Cdk5 is important for microtubule organization, nuclear movement, and neuronal migration. Cell 114, 469-482. doi: 10.1016/S0092-8674(03)00605-6

Yang, T., Sun, Y., Zhang, F., Zhu, Y., Shi, L., Li, H., et al. (2012). POSH localizes activated Racl to control the formation of cytoplasmic dilation of the leading process and neuronal migration. Cell Rep. 2, 640-651. doi: 10.1016/j.celrep.2012.08.007

Yap, C. C., Vakulenko, M., Kruczek, K., Motamedi, B., Digilio, L., Liu, J. S., et al. (2012). Doublecortin (DCX) mediates endocytosis of neurofascin independently of microtubule binding. J. Neurosci. 32, 7439-7453. doi: 10.1523/JNEUROSCI.5318-11.2012

Yap, C. C., and Winckler, B. (2015). Adapting for endocytosis: roles for endocytic sorting adaptors in directing neural development. Front. Cell. Neurosci. 9:119. doi: $10.3389 /$ fncel.2015.00119

Ye, T., Ip, J. P., Fu, A. K., and Ip, N. Y. (2014). Cdk5-mediated phosphorylation of RapGEF2 controls neuronal migration in the developing cerebral cortex. Nat. Commun. 5, 4826. doi: 10.1038/ncomms5826

Zhang, C., Mejia, L. A., Huang, J., Valnegri, P., Bennett, E. J., Anckar, J., et al. (2013a). The X-linked intellectual disability protein PHF6 associates with the PAF1 complex and regulates neuronal migration in the mammalian brain. Neuron 78, 986-993. doi: 10.1016/j.neuron.2013.04.021

Zhang, J., Neal, J., Lian, G., Hu, J., Lu, J., and Sheen, V. (2013b). Filamin A regulates neuronal migration through brefeldin $\mathrm{A}$-inhibited guanine exchange factor 2-dependent Arf1 activation. J. Neurosci. 33, 15735-15746. doi: 10.1523/JNEUROSCI.1939-13.2013

Zhang, X., Lei, K., Yuan, X., Wu, X., Zhuang, Y., Xu, T., et al. (2009). SUN1/2 and Syne/Nesprin-1/2 complexes connect centrosome to the nucleus during neurogenesis and neuronal migration in mice. Neuron 64, 173-187. doi: 10.1016/j.neuron.2009.08.018

Conflict of Interest Statement: The author declares that the research was conducted in the absence of any commercial or financial relationships that could be construed as a potential conflict of interest.

Copyright () 2015 Kawauchi. This is an open-access article distributed under the terms of the Creative Commons Attribution License (CC BY). The use, distribution or reproduction in other forums is permitted, provided the original author(s) or licensor are credited and that the original publication in this journal is cited, in accordance with accepted academic practice. No use, distribution or reproduction is permitted which does not comply with these terms. 